\title{
BUKU SUPLEMEN BERBASIS ANDROID SEBAGAI MEDIA PEMBELAJARAN PADA MATERI GELOMBANG ELEKTROMAGNETIK UNTUK PESERTA DIDIK SMA
}

\author{
Dhita Kusuma Dewi ${ }^{\text {a) }}$, I Made Astra ${ }^{\text {b) }}$, Dwi Susanti ${ }^{\text {c) }}$ \\ Prodi Pendidikan Fisika, Fakultas Matematika dan Ilmu Pengetahuan Alam, Universitas Negeri Jakarta \\ Jalan Rawamangun Muka No.1 Rawamangun, Jakarta Timur, Indonesia
}

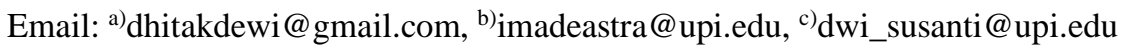

\begin{abstract}
Abstrak
Penelitian ini bertujuan untuk mengembangkan dan menghasilkan produk berupa buku suplemen berbasis android yang dapat menunjang pembelajaran fisika SMA pada materi gelombang elektromagnetik. Metode penelitian yang digunakan adalah Research and Development (R\&D) yang mengacu pada model Dick \& Carey. Berdasarkan analisis kebutuhan pada 49 peserta didik kelas XI SMA di Jakarta diperoleh hasil bahwa 75.5\% sumber belajar yang digunakan adalah buku pelajaran fisika tetapi $71.4 \%$ diantaranya merasa kesulitan untuk mempelajari fisika dari sumber belajarnya sehingga munculah buku suplemen berbasis android ini sebagai media belajar tambahan yang dapat digunakan peserta didik diluar kegiatan belajar mengajar (KBM). Buku suplemen ini berisi mengenai materi gelombang elektromagnetik yang disajikan dalam versi digital dan dilengkapi dengan video pendukung serta latihan soal. Berdasarkan hasil validasi diperoleh persentase sebesar $95,8 \%$ oleh ahli materi dan $87 \%$ oleh ahli media dengan interpretasi sangat layak. Uji efektivitas menunjukkan hasil uji gain sebesar 0,517 dengan interpretasi sedang. Berdasarkan uji kelayakan dan uji efektifitas maka dapat disimpulkan bahwa buku suplemen berbasis android pada materi gelombang elektromagnetik untuk peserta didik SMA ini dapat dikategorikan sebagai bahan ajar mandiri yang layak digunakan.
\end{abstract}

Kata-kata kunci: buku suplemen, android, gelombang elektromagnetik

\begin{abstract}
This research aims to develop and produce products in the form of supplement book based on Android that can support high school physics learning on electromagnetic wave materials. A method that used in this research is Research and Development (R\&D) refers to a model of Dick \& Carey. Based on requirement analysis, it was found that $75.5 \%$ of learning resources which used is physics textbooks but $71.4 \%$ of them found it difficult to learn physics from their learning sources so this supplement book based on Android appeared as an additional learning media that can use learners outside of teaching and learning activities (KBM). This supplement book contains electromagnetic wave material presented in digital version and comes with supporting video and exercise questions. Based on the validation results obtained a percentage of $95.8 \%$ by material expert and $87 \%$ by media experts with a very feasible interpretation. Effectiveness test shows the result of the gain test of 0.517 with moderate interpretation. Based on the feasibility test and the effectiveness test, so it can be concluded that supplement book based on android of electromagnetic waves material for high school students can be categorized as self-sufficient teaching materials that are suitable for use.
\end{abstract}

Keywords: supplement book, android, electromagnetic waves 


\section{PENDAHULUAN}

Saat ini, teknologi informasi dan komunikasi semakin berkembang. Perkembangan teknologi informasi dan komunikasi berpengaruh terhadap bidang pendidikan pada proses pembelajaran. Untuk menghadapi pembelajaran di abad 21, setiap orang harus memiliki keterampilan berpikir kritis, pengetahuan dan kemampuan literasi digital, literasi informasi, literasi media dan menguasai teknologi informasi dan komunikasi [1]. Sebagai cara untuk menyelaraskan antara teknologi dan proses pembelajaran pendidikan, saat ini proses pembelajaran peserta didik dikelilingi oleh berbagai sumber/media belajar dan layanan belajar elektronik yang mampu mendukung kegiatan belajar mengajar, salah satunya dengan memanfaatkan smartphone.

Pada survei dari 132,7 juta orang yang dilakukan oleh Asosiasi Penyelenggara Jasa Internet Indonesia (APJII) menunjukkan bahwa rata-rata pengguna internet Indonesia menggunakan smartphone dan 18,4\% atau sekitar 24,4 juta diantaranya berusia 10-24 tahun. Hal tersebut menunjukkan bahwa banyaknya pengguna internet di usia muda serta ada sekitar $69,8 \%$ pengguna internet adalah seorang pelajar [2].

Hasil analisis kebutuhan yang disebar ke tiga SMA di Jakarta dengan responden sebanyak 49 peserta didik memperlihatkan bahwa $87.8 \%$ diantaranya menggunakan sistem operasi Android dan 12.2\% lainnya menggunakan iOS. Kemudian rata-rata peserta didik membuka/mengecek smatphone setiap jam bahkan setiap menit sekali. Hal tersebut menunjukkan jika sistem operasi Android menjadi salah satu sistem operasi yang populer di kalangan pelajar dan seringnya peserta didik mengecek smartphone lebih sering dibanding membuka buku fisika karena dari hasil kuisioner rata-rata membuka buku pelajaran fisika hanya saat diberi tugas oleh guru dan dua kali seminggu saat mata fisika berlangsung saja.

Dari minimnya penggunaan buku teks fisika dalam kegiatan peserta didik diluar kegiatan belajar mengajar (KBM) maka dibutuhkan suatu media dalam pembelajaran yang diharapkan mampu untuk menumbuhkan minat peserta didik agar dapat mempelajari fisika diluar KBM. Media pembelajaran digunakan untuk mengatasi keterbatasan ruang, waktu, dan tenaga sehingga sangat diperlukan dalam pembelajaran agar interaksi antara guru dan siswa semakin efektif. Minimnya media yang digunakan terkadang menjadi hambatan dalam proses pembelajaran sehingga informasi bisa menjadi kurang maksimal dalam penyampaiannya. Cara penyajian bahan pelajaran yang tanpa variasi atau kurangnya sarana dan prasarana menjadi salah satu hambatan dalam penyampaian materi pada proses pembelajaran. Oleh sebab itu dibutuhkan suatu media penunjang yang dapat meningkatkan minat dan motivasi siswa dalam belajar sehingga lebih tertarik dalam mempelajari fisika.

Perkembangan teknologi telah menciptakan terobosan dalam pembelajaran sebagai contohnya siswa sering menggunakan perangkat komunikasi bergerak dan internet menjadi tren baru yang memiliki kemungkinan untuk mengatur pembelajaran bergerak (m-learning) karena siswa tidak harus selalu hadir dalam proses belajar dan dapat mengakses materi pembelajaran kapan dan dimana saja [3]. Seiring dengan berkembangnya teknologi tersebut, sangat memungkinkan untuk mengembangkan sebuah media pembelajaran yang tadinya dalam bentuk cetak, diubah ke dalam bentuk digital/elektronik, misalnya buku suplemen berbasis android. Penggunaan buku suplemen ini dibutuhkan peserta didik sebagai buku penunjang atau buku tambahan selain buku teks yang mereka miliki. Perubahan bentuk penggunaan buku suplemen dalam pembelajaran ini diharapkan mampu mengikuti perkembangan dunia pendidikan di masa mendatang yang memberikan kemudahan untuk belajar tanpa batas ruang dan waktu serta sesuai dengan pembelajaran masa kini dalam prinsip pembelajaran kurikulum 2013.

Dalam kegiatan belajar mengajar peserta didik di kelas, diperlukan media pembelajaran untuk menunjang pembelajarannya, salah satunya adalah buku teks. Menurut Peraturan Menteri Pendidikan Nasional Republik Indonesia Nomor 2 tahun 2008 tertulis bahwa selain buku teks, pendidik juga dapat menggunakan buku panduan pendidik, buku pengayaan, dan buku referensi dalam proses pembelajaran untuk menambah pengetahuan dan wawasan peserta didik [4].

Dalam penggunaannya, buku suplemen termasuk ke dalam buku nonteks pelajaran sehingga akan berbeda dengan buku teks pelajaran di sekolah. Untuk itu, untuk mengetahui ciri-ciri buku suplemen maka kita harus mengetahui perbedaan dari buku teks dan buku suplemen terlebih dahulu.

Berikut perbedaan penggunaan buku teks dan buku suplemen yang dikutip dari Depdiknas RI [5]. 
TABEL 1. Perbedaan Buku Teks dan Buku Suplemen

\begin{tabular}{|c|c|c|c|}
\hline No & Karakteristik & Buku Teks & Buku Suplemen \\
\hline 1 & Target & $\begin{array}{l}\text { Terdiri dari materi yang ditulis } \\
\text { dan dipahami siswa dalam } \\
\text { satuan pendidikan }\end{array}$ & $\begin{array}{l}\text { Menambah pengetahuan siswa } \\
\text { dan guru dalam satuan } \\
\text { pendidikan }\end{array}$ \\
\hline 2 & $\begin{array}{l}\text { Kegunaan dalam } \\
\text { satuan pendidikan }\end{array}$ & Sumber utama & Pelengkap \\
\hline 3 & $\begin{array}{l}\text { Kedudukan dalam } \\
\text { satuan pendidikan }\end{array}$ & Wajib & $\begin{array}{l}\text { Bukan sebagai sumber utama, } \\
\text { melainkan pendukung }\end{array}$ \\
\hline 4 & $\begin{array}{l}\text { Kegunaan sebagai alat } \\
\text { pendukung }\end{array}$ & Tinggi & Tidak tinggi \\
\hline 5 & Keterangan penulisan & Berkaitan dengan kurikulum & $\begin{array}{l}\text { Tidak terkait dengan kurikulum } \\
\text { (mata pelajaran sains, } \\
\text { kebutuhan hidup, perencanaan } \\
\text { atau perkembangan zaman, } \\
\text { pengalaman hidup) }\end{array}$ \\
\hline 6 & Bantuan guru & Wajib & Tidak wajib \\
\hline 7 & Anatomi buku & $\begin{array}{l}\text { Berisi materi pelajaran yang } \\
\text { lengkap }\end{array}$ & \\
\hline 8 & Pengguna & Mayoritas siswa & Tidak didominasi siswa \\
\hline 9 & Tempat penggunaan & Kebanyakan di kelas/sekolah & $\begin{array}{l}\text { Tidak didominasi kelas/sekolah } \\
\text { (rumah, ruang tunggu, tempat } \\
\text { umum, dll) }\end{array}$ \\
\hline
\end{tabular}

Buku pelengkap dapat memenuhi kebutuhan siswa yang dapat mengembangkan kepribadian, memperluas pengetahuan, dan meningkatkan keterampilan hidup yang bermanfaat dalam membangun kemandirian sosial [6]. Dalam mengembangkan buku suplemen, harus memperhatikan komponen dasar buku yang berkualitas, yaitu dari aspek isi/materi, aspek penyajian, aspek bahasa/keterbacaan, aspek grafika, dan aspek keamanan [7].

Android merupakan sistem operasi smartphone dan tablet yang merupakan modifikasi dari linux dengan menggunakan bahasa Java dan sebagian besar memiliki kode android yang bersifat open source sehingga memudahkan dan memungkinkan pengguna untuk mengembangkan aplikasinya sendiri. Penelitian sebelumnya menunjukkan bahwa platform android sangat memungkinkan untuk mengembangkan berbagai media pembelajaran berbasis mobile [8], atau aplikasi yang dirancang khusus seperti handout [9], aplikasi dengan augmented reality [10], aplikasi web yang dikemas dalam aplikasi android [11], atau bahkan media pembelajaran grafis semacam komik [12-14].

Semakin majunya perkembangan teknologi saat ini serta kemudahan seorang pengembang untuk membuat aplikasi android maka dibutuhkannya suatu media dengan kecanggihan perangkat teknologi dalam dunia pendidikan. Oleh karena itu, untuk mendukung segala aspek perkembangan zaman di abad 21 ini diperlukan suatu pengembangan aplikasi android sebagai media pembelajaran sebagai contoh khususnya adalah pengembangan sebuah aplikasi yang membuat media pembelajaran berupa buku suplemen berbasis android pada materi gelombang elektromagnetik untuk peserta didik SMA.

\section{METODE PENELITIAN}

Metode penelitian yang digunakan adalah Research and Development (R\&D) yang mengacu pada model Dick \& Carey dengan tahapan: 1) mengidentifikasi tujuan pembelajaran; 2) melakukan analisis instruksional; 3) menganalisis karakteristik peserta didik dan konteks pembelajaran; 4) merumuskan tujuan pembelajaran khusus; 5) mengembangkan instrumen penilaian; 6) mengembangkan strategi pembelajaran; 7) mengembangkan dan memilih bahan ajar; 8) merancang dan mengembangkan evaluasi formatif; 9) melakukan revisi terhadap program pembelajaran; 10) merancang dan mengembangkan evaluasi sumatif. Pada tahapan desain produk, dilakukan studi pendahuluan dengan melakukan perbandingan terhadap penelitian sebelumnya mengenai pengembangan buku dan lebar kerja [15-19]. 
Buku suplemen gelombang elektromagnetik ini dikembangkan berdasarkan analisis kebutuhan yang disebar ke peserta didik yang kemudian disusun materi sesuai dengan kompetensi dasar 3.10 kelas XI semester genap yang disesuaikan juga dengan karakteristik peserta didik dan konteks pembelajarannya. Penelitian ini dilakukan di SMA Negeri 103 Jakarta dengan responden 36 peserta didik kelas XI MIPA.

Instrumen penelitian dengan menyebar angket, yaitu angket analisis kebutuhan, uji validasi kelayakan para ahli (ahli media dan ahli materi) serta uji coba produk oleh guru dan peserta didik. Data yang diperoleh dari uji validasi dan uji coba di hitung dengan skala likert. Terdapat lima kategori penilaian berdasar pada kriteria interpretasi masing-masing skor [20], yaitu:

TABEL 3. Skala likert untuk kategori penilaian

\begin{tabular}{ccc}
\hline No. & Kategori Penilaian & Bobot Skor \\
\hline 1 & Sangat tidak setuju & 1 \\
2 & Kurang setuju & 2 \\
3 & Cukup setuju & 3 \\
4 & Setuju & 4 \\
5 & Sangat setuju & 5 \\
\hline
\end{tabular}

Kemudian skor dihitung berdasarkan skor perolehan pada masing-masing aspek:

$\%$ interpretasi skor $=\frac{\sum \text { skor peralehan }}{\sum \text { skor maksimum }} \times 100 \%$

Persentase skor yang telah dihitung kemudian dicocokkan pada tabel interpretasi persentase pada skala likert, yaitu sebagai berikut [21].

TABEL 4. Interpretasi persentase skala likert

\begin{tabular}{ccc}
\hline No. & Interpretasi & Persentase \\
\hline 1 & Sangat kurang layak & $0 \%-20 \%$ \\
2 & Kurang layak & $21 \%-40 \%$ \\
3 & Cukup layak & $41 \%-60 \%$ \\
4 & Layak & $61 \%-80 \%$ \\
5 & Sangat layak & $81 \%-100 \%$ \\
\hline
\end{tabular}

Uji coba produk dilakukan oleh peserta didik kelas XI SMA dengan melaksanakan test sebelum dan sesudah menggunakan produk untuk mengetahui peningkatan hasil belajar peserta didik dengan menggunakan uji gain ternormalisasi.

\section{HASIL DAN PEMBAHASAN}

Buku suplemen berbasis android yang dikembangkan berisi mengenai materi gelombang elektromagnetik yang di dalamnya terdapat penjelasan tentang apa itu gelombang elektromagnetik, spektrum-spektrum gelombang elektromagnetik, manfaat dan bahaya dari masing-masing spektrum gelombang elektromagnetik yang dilengkapi dengan video pendukung untuk setiap spektrumnya. Di akhir pembelajaran terdapat rangkuman dan juga tes formatif agar dapat mengingat kembali materi yang telah dipelajari. Berikut adalah beberapa tampilan dari produk yang telah dibuat.

1. Panduan

Pada halaman ini berisi mengenai cerita singkat tujuan dibuatnya aplikasi dan apa yang tersedia di dalam aplikasi. 


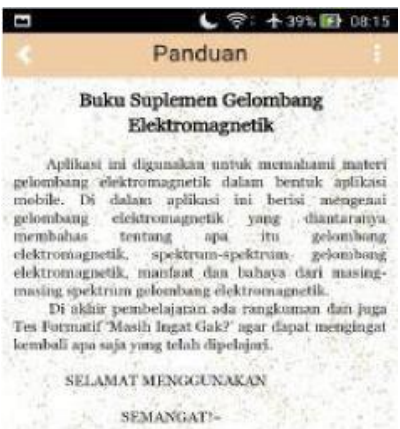

GAMBAR 1. Tampilan Laman Panduan

2. Menu utama

Menu utama merupakan tampilan awal dari buku suplemen berbasis android. Pada tampilan menu utama ini berisi panduan, peta konsep, daftar materi gelombang elektromagnetik, rangkuman, latihan soal, tentang penulis, dan sumber referensi.
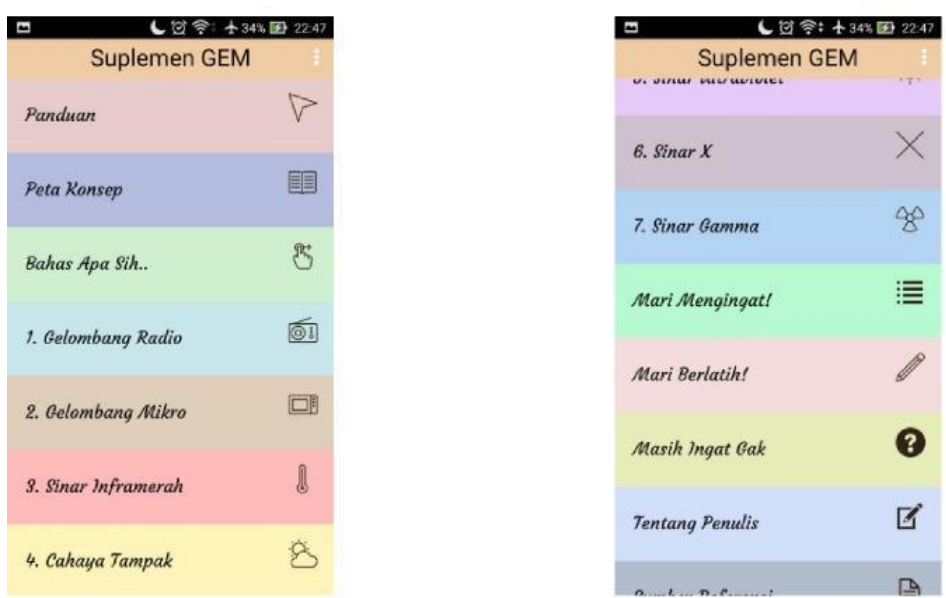

GAMBAR 2. (a) Tampilan menu utama, (b) Tampilan laman menu utama setelah di scroll

\section{Peta Konsep}

Peta konsep menghubungkan point-point topik yang akan dibahas pada aplikasi ini.

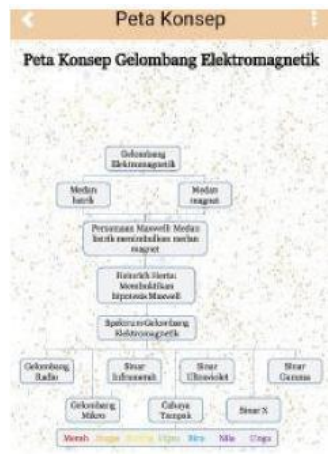

4. Halaman Materi

GAMBAR 3. Tampilan Laman Peta Konsep

Halaman ini berisi mengenai pembahasan masing-masing spektrum gelombang elektromagnetik yang akan dipelajari. Halaman materi terdiri dari pengetahuan mengenai pengertian, sejarah, manfaat, bahaya, dan fakta-fakta lainnya seputar spektrum gelombang elektromagnetik yang disertai dengan tab video pendukung. 

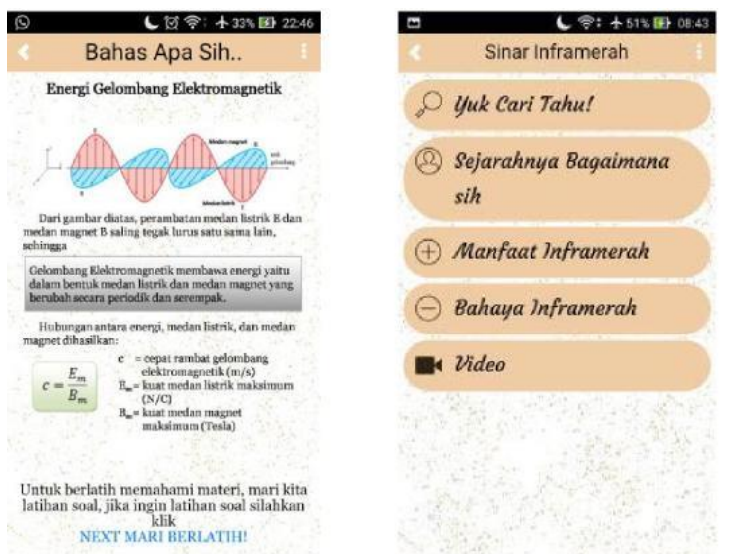
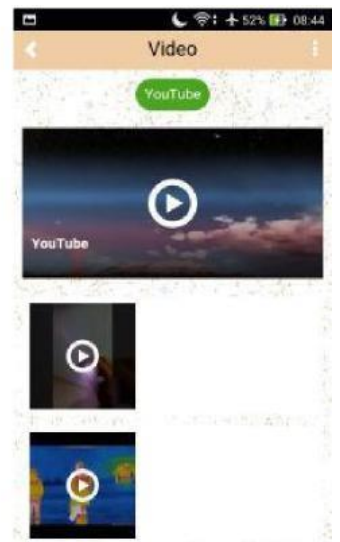

GAMBAR 4. (a) Contoh tampilan dari laman Bahas Apa Sih, (b) Contoh tampilan awal dari laman materi pada spektrum sinar inframerah, (c) Tampilan laman video pendukung.

5. Masih Ingat Gak

Halaman ini berisi kumpulan soal agar peserta didik dapat mengukur kemampuannya untuk menjawab soal dengan benar sehingga dapat mengetahui apakah dia masih mengingat materi yang sudah dipelajarinya atau tidak.

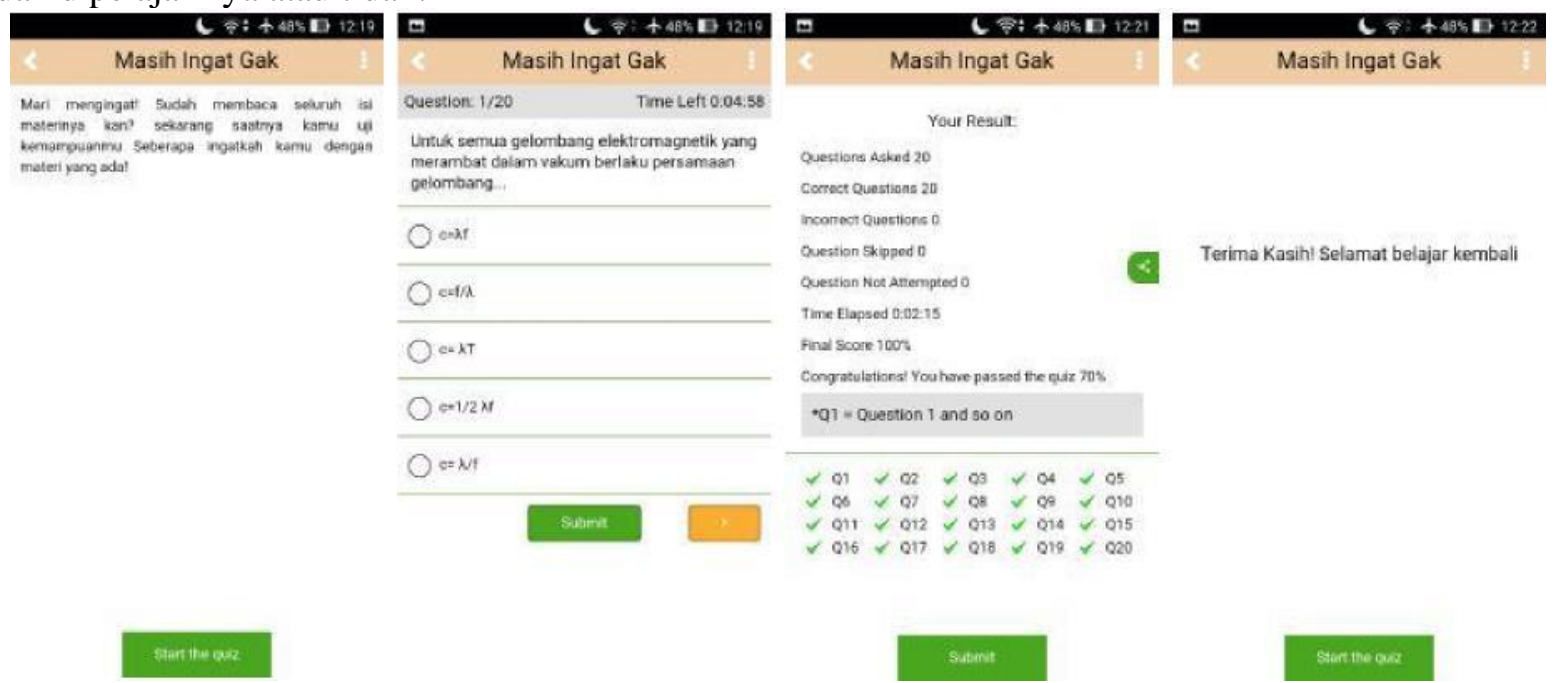

GAMBAR 5. (a) Tampilan awal Quiz gelombang elektromagnetik, (b) Contoh tampilan soal dan pilihan jawaban, (c) Tampilan laman quiz setelah dijawab pertanyaannya, (d) Tampilan akhir berupa ucapan terima kasih

\section{Sumber Referensi}

Halaman ini berisi referensi yang digunakan dalam pembuatan materi, latihan soal.

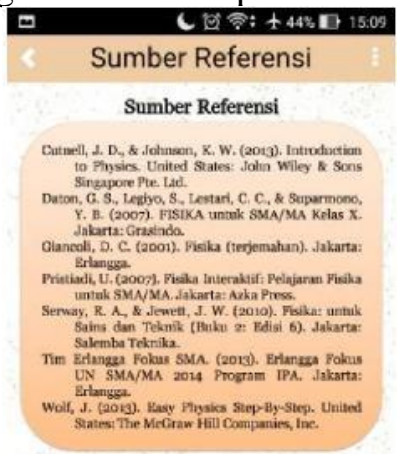

GAMBAR 6. Tampilan laman Sumber Referensi 
Produk yang telah selesai dibuat, harus diuji validasi terlebih dahulu sehingga didapatkan data hasil penelitian. Deskripsi data hasil penelitian dapat digunakan untuk menganalisis tingkat kelayakan produk sebagai bahan ajar mandiri. Berikut hasil uji validasi oleh ahli materi dan media.

TABEL 6. Hasil uji kelayakan

\begin{tabular}{ccc}
\hline \multirow{2}{*}{ Ahli } & \multicolumn{2}{c}{ Hasil Uji Kelayakan } \\
\cline { 2 - 3 } & Persentase (\%) & Interpretasi \\
\hline Ahli Materi & $95,8 \%$ & Sangat layak \\
Ahli Media & $87 \%$ & Sangat layak \\
\hline
\end{tabular}

Hasil uji validasi oleh ahli materi diperoleh persentase persentase rata-rata untuk capaian seluruh aspek sebesar 95,8\%. Validator ahli materi memberikan masukan untuk menambahkan aplikasi gelombang elektromagnetik pada teknologi atau kehidupan terkini yang relevan. Kemudian hasil uji validasi oleh ahli media diperoleh persentase rata-rata untuk capaian seluruh aspek sebesar $87 \%$. Validator ahli media memberikan masukan untuk memperbesar huruf tulisan, terlalu banyak kata per halaman untuk dikurangi, pada tampilan video untuk diberi link atau langsung tertera di materi pokok (tidak pada tab baru). Setelah dilakukan revisi produk sesuai dengan saran dari para ahli, selanjutnya melakukan uji coba produk kepada guru fisika dan peserta didik SMA.

Hasil uji coba produk oleh guru fisika SMAN 103 Jakarta diperoleh persentase rata-rata dari seluruh aspek sebesar $82 \%$. Kemudian hasil uji coba produk oleh peserta didik diperoleh persentase rata-rata dari seluruh aspek sebesar $83,8 \%$. Hasil tersebut menunjukkan bahwa produk yang dikembangkan memiliki interpretasi sangat layak dan dapat diterima dengan sangat baik oleh peserta didik sebagai bahan ajar mandiri.

Selain diberikan angket uji coba produk, peserta didik juga melakukan uji efektivitas dengan memberikan soal pre test sebelum mencoba produk dan soal post test setelah mencoba produk untuk mengetahui tingkat keberhasilan pembelajaran. Perhitungan dilakukan dengan menggunakan Uji gain ternormalisasi.

TABEL 7. Hasil uji efektivitas

\begin{tabular}{ccc}
\hline \multirow{2}{*}{ Ahli } & \multicolumn{2}{c}{ Hasil Uji Coba Produk } \\
\cline { 2 - 3 } & Persentase (\%) & Interpretasi \\
\hline Guru Fisika SMA & $82 \%$ & Sangat layak \\
Peserta didik kelas XI MIPA & $83,8 \%$ & Sangat layak \\
\hline
\end{tabular}

Dengan menggunakan perhitungan uji gain, dinyatakan terjadi peningkatan pengetahuan dengan nilai rata-rata pre test 38,6 dan rata-rata nilai post test 70,8 . Nilai tersebut menunjukkan bahwa terjadi peningkatan pengetahuan dengan skor gain 0,517. Skor tersebut menggambarkan peningkatan pengetahuan yang terjadi dengan interpretasi sedang.

TABEL 8. Hasil pretest dan postest

\begin{tabular}{cc}
\hline Komponen & Nilai rata-rata \\
\hline Pre test & 38,6 \\
Post test & 70,8 \\
\hline
\end{tabular}

\section{SIMPULAN}

Berdasarkan hasil uji coba produk dan hasil uji efektivitas, persentase rata-rata untuk capaian keseluruhan dalam skala likert menunjukkan bahwa produk yang dikembangkan, yaitu buku suplemen pada materi gelombang elektromagnetik berbasis android ini sangat layak untuk digunakan sebagai bahan ajar mandiri dan mampu meningkatkan pengetahuan peserta didik sesuai dengan perhitungan menggunakan uji gain. Beberapa saran yang dapat diberikan untuk pengembangan selanjutnya adalah lebih mengembangkan materi pada teknologi atau kehidupan terkini yang relevan, mengembangkan 
buku suplemen berbasis android pada materi lain pada seluruh materi di jenjang SMA, dan mengembangkan buku suplemen dengan menggunakan model pembelajaran kontekstual.

\section{REFERENSI}

[1] Frydenberg, Mark, and Diana Andone. "Learning for 21st Century Skills." International Conference on Information Society. London: IEEE, 2011. 314-318.

[2] Asosiasi Penyelenggara Jasa Internet Indonesia. "Survei Internet APJII 2016." APJII. 2016. https://apjii.or.id/survei2016 (accessed Januari 17, 2018).

[3] Astra, I Made, Hadi Nasbey, and Aditiya Nugraha. "Development of an Android Application in the Form of a Simulation Lab as Learning Media for Senior High School Students." Eurasia Journal of Mathematics, Science \& Technology Education 11, no. 5 (2015): 1081-1088.

[4] Kemendiknas. Peraturan Menteri Pendidikan Nasional Nomor 02 Tahun 2008 Pasal 6 Ayat 2 dan 3 tentang Penggunaan Buku di Satuan Pendidikan. Jakarta: Departemen Pendidikan Nasional, 2008.

[5] Rokhmah, Aulia. Penyusunan Buku Suplemen Mapel Geografi SMA Kelas XI Semester I Kurikulum 2013 Berbasis Android. Semarang: Universitas Negeri Semarang, 2015.

[6] Maryam, Siti. "Strengthening the Character: Uphold Ethics in Indonesian Language Study Pass by Supplementary Books." EDUCARE: International Journal for Educational Studies, 2012: 3950.

[7] Muzakir. Penulisan Buku Teks yang Berkualitas. Bandung: Universitas Pendidikan Indonesia, 2013, 13-15.

[8] I. A. D. Astuti, R. A. Sumarni, and D. L. Saraswati, "Pengembangan Media Pembelajaran Fisika Mobile Learning berbasis Android", jpppf, vol. 3, no. 1, pp. 57 - 62, 2017.

[9] S. Syahrowardi and A. H. Permana, "Desain Handout Multimedia Menggunakan 3D Pageflip Professional untuk Media Pembelajaran pada Sistem Android”, jpppf, vol. 2, no. 1, pp. 89 - 96, 2016.

[10] D. Ambarwulan and D. Muliyati, "The Design of Augmented Reality Application as Learning Media Marker-Based for Android Smartphone", jpppf, vol. 2, no. 1, pp. 73 - 80, Jun. 2016.

[11] B. R. Simanjuntak, D. Desnita, and E. Budi, "The Development of Web-based Instructional Media for Teaching Wave Physics on Android Mobile", jpppf, vol. 4, no. 1, pp. 1 - 10, Jun. 2018.

[12] S. Sarinah, D. Muliyati, and I. M. Astra, "Merancang Komik Cerita Tokoh Menggunakan Aplikasi Comicker sebagai Media Pembelajaran", jpppf, vol. 2, no. 1, pp. 103 - 110, 2016.

[13] F. Savila, I. M. Astra, and D. Muliyati, "Pengembangan Komik Biografi Sir Isaac Newton Sebagai Media Pembelajaran Fisika Menggunakan Aplikasi Paint Tool SAI." Gravity: Jurnal Ilmiah Penelitian dan Pembelajaran Fisika, vol.4, no.2, 2018.

[14] D. Muliyati, S. Siswoyo, D. Rahmadini, "Komik efek fotolistrik : komik sejarah efek fotolistrik dari 5 ilmuwan." CV Green Circle Digital, 2017.

[15] D. F. Saputri, S. Fadilah, and W. Wahyudi, "Efektivitas Penggunaan Buku Ajar Fisika Matematika Berbasis Inkuiri dalam Perkuliahan Fisika Matematika", jpppf, vol. 2, no. 2, pp. 7 $14,2016$.

[16] D. Desnita, N. Fadilah, and E. Budi, "Pengembangan Buku Pengayaan Kajian Fisis Peristiwa Angin Puting Beliung untuk Siswa SMA", jpppf, vol. 2, no. 2, pp. 97 - 104, 2016.

[17] S. Maulana, D. Desnita, and R. Raihanati, "The Development of Knowledge Enrichment Books Concerning Ice and Snow Physical Studies for High-School Students", jpppf, vol. 4, no. 2, pp. 83 - 90, 2018.

[18] H. Anis and A. M. Yusuf, "Implementasi Lembar Kerja Berbasis Pertanyaan Produktif untuk Meningkatkan Kemampuan Berinkuiri Siswa SMA”, jpppf, vol. 2, no. 2, pp. 23 - 30, 2016.

[19] D. Saepuzaman and Y. Yustiandi, "Pengembangan Alat Peraga dan Lembar Kerja Percobaan Penentuan Koefisien Restitusi untuk Meningkatkan Kemampuan Siswa Bereksperimen", jpppf, vol. 3, no. 2, pp. 145 - 150, 2017.

[20] Sugiyono. Metode Penelitian Kuantitatif, Kualitatif dan R \& D. Bandung: Alfabeta, 2012.

[21] Sundayana, Rostina. Statistika Penelitian Pendidikan. Bandung: Alfabeta, 2014. 